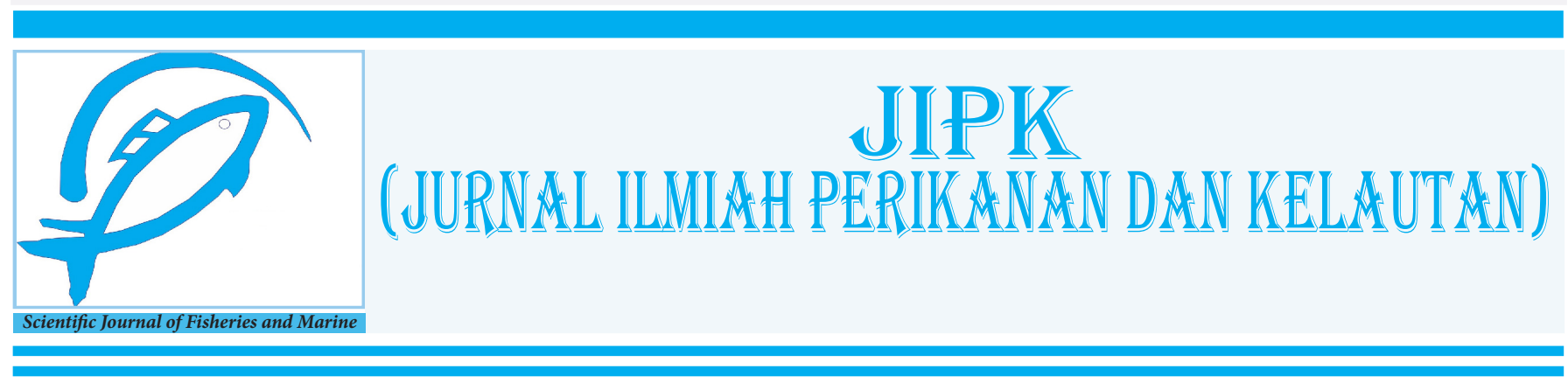

Short Communication

\title{
New Report on the Occurrence of Gregarine Parasites in Wild Species of Macrobrachium rosenbergii from Setiu Lagoon, Terengganu, Malaysia
}

Mohd Ihwan Zakariah"1,2, Hassan Haji Mohd Daud ${ }^{2}$, Mhd. Ikhwanuddin Abdullah ${ }^{1,3}$, Wahidah Wahab $^{1}$, Farizan Abdullah${ }^{1}$, Nor Asma Husna Mohammed Yusoff ${ }^{1}$, Ahmad Shuhaimi Draman ${ }^{1}$, and Marina Hassan ${ }^{1,3 *}$ (iD)

${ }^{1}$ Higher Institution Centres of Excellence, Institute of Tropical Aquaculture and Fisheries, (AKUATROP), Universiti Malaysia Terengganu, Kuala Nerus, Terengganu, 21030. Malaysia

${ }^{2}$ Faculty of Veterinary Medicine, Universiti Putra Malaysia, Serdang, Selangor, 43400. Malaysia

${ }^{3}$ STU-UMT Joint Shellfish Research Laboratory, Shantou University, Shantou, 515063. China

\section{OPEN $\bigcirc$ ACCESS}

\section{ARTICLE INFO}

Received: June 18, 2021

Accepted: October 11, 2021

Published: October 16, 2021

*) Corresponding author:

E-mail: ihwanz@umt.edu.my, mari-

na@umt.edu.my

Keywords:

Aquaculture

Prawn

Macrobrachium rosenbergii

Gregarine

Protozoan Parasites

This is an open access article under the CC BY-NC-SA license (https://creativecommons.org/ licenses/by-nc-sa/4.0/)

\section{Abstract}

Studies on the parasite of prawns are likely to be important due to the commercial value of the prawn. Investigation study about gregarine parasites of $M$. rosenbergii in Malaysia is still lacking. Objective of this study is to determine the occurrence of gregarine parasites in shrimp, $M$. rosenbergii from Setiu Lagoon, Terengganu. The study was done specifically to observe the prevalence and the mean intensity of the parasites which include the morphological prevalence and parasitological study. Prevalence of the parasites in this study is $42.4 \%$ with $95 \%$ Cumulative Index (CI) $25.6 \%$ to $59.3 \%$ and value of Odd Ratio (OR) is $0.74(\mathrm{CI}=0.29$ to 1.88$)$. Two structures of the gregarine which is gamont and syzygy found in this study are closely related to morphology characteristic of gregarine in the previous report.

Cite this as: Zakariah, M. I., Daud, H. H. M., Abdullah, M. I., Wahab, W., Abdullah, F., Yusoff, N. A. H. M., Draman, A. S., \& Hassan, M. (2022). New Report on The Occurrence of Gregarine Parasites in Wild Species of Macrobrachium rosenbergii from Setiu Lagoon, Terengganu, Malaysia. Jurnal Ilmiah Perikanan dan Kelautan, 14(1):142-149. http://doi.org/10.20473/jipk. v14i1.31087 


\section{Introduction}

Infection of Apicomplexan protozoan genus $\mathrm{Nema-}$ topsis has ordinarily been reported in molluses, which acts as the intermediate host with crustaceans as the definitive host (Tuntiwaranuruk et al., 2004) and also found in giant freshwater prawn (Lightner, 1996). In Thailand, the infestation of gregarine Nematopsis spp. sporozoites infections have been extensively reported in bivalve species, such as cockles (A. granosa), mytilid mussels (Perna viridis and $A$. arcuatula), and venerid clams (P. undulate) (Tuntiwaranuruk et al., 2004). Nematopsis sp., Tylocephalum sp., digenetic trematodes and ciliates were also reported from $C$. iredale $i$ in the Philippines (Erazo-Pagador, 2010).

An extensive survey of estuarine crabs in Kerala, India revealed the presence of three species of cephaline gregarines parasites belonging to the genus Nematopsis were found. The objective of this study is to determine the occurrence of the gregarine parasite in M. rosenbergii from Setiu Lagoon, Terengganu. Besides, there is no report of gregarine species that infected crab but there is a new report of gregarine infection in the prawn and bivalves in Malaysia. The findings were significant and contributed new knowledge to the research community, especially on gregarine parasites infection in the commercially important crustacean culture worldwide.

Moreover, some studies proved that gymnospores and oocysts of gregarines are usually concomitant with a pivotal, nonthreatening inflammatory response and there is no serious effect or damage to the host (Hofman et al., 2009). Gymnospores need marine arthropods such as crabs or shrimps to complete their life cycle (Prytherch, 1940; Sindermann, 1990). Hence, the multiplication of gregarines is limited to crustacean and mollusc, respectively. Report of the occurrence of gregarine parasites are published but mass mortality cases of crustaceans and bivalves caused by gregarine have not yet been reported in Malaysia. However, the previous report mention the mass mortality of cockles and clams in Portugal had been associated with this parasite (Yee and Hassan, 2020).

In Malaysia, a monitoring programme on the molluscan health focusing on the Office International des Epizooties (OIE) revealed that gregarine was the most frequently listed parasite from 1999 until 2009, which showed that gymnospores of gregarine parasites were parasites most frequently encountered in tropical oysters (Crassostrea iredalei) and blood cockles (Anadara granosa) respectively (OIE, 2016). Hence, the previous study observation did not find any significant health effects.
A survey of OIE listed parasites in tropical oysters (C. iredalei) in 2000 and 2003 reported the prevalence of gregarine Nematopsis spp. oocyte ranging from 33\% to $73 \%$ (Kua and Taha, 2004). Despite, the commercial value and gradual increase in the production of crustacean species in Malaysia, there has been no report or any specific study on problematic diseases regarding these gregarine parasites. Several reports on the diseases, particularly those caused by parasites, have been described by various shellfish in other countries (Sindermann, 1990).

The objective of this study is to determine the occurrence of gregarine parasites in shrimp, M. rosenbergii from Setiu Lagoon, Terengganu. Nevertheless, a crustacean health monitoring programme has not yet been initiated by focusing on the OIE listed parasites. Subsequently, there is a lack of study about gregarine parasites in Malaysia. Most of the study is focusing on the species of mollusc that were previously reported by Kua et al. (2013). Ubiquitously, the infections of these types of parasites are commonly reported from bivalve and shrimp (Prasadan and Janardan, 2001). They report that all gregarines are known to inhabit crabs and prawns (Tuntiwaranuruk et al., 2004).

\section{Materials and Methods}

\subsection{Samples Collection and Diagnosis Study}

Setiu lagoon is a renowned wetland in the northern part of Terengganu and is extremely unique as it contains many ecosystems such as lagoon, rivers, mangrove forest, seagrass bed, beach, and small islands. This complete ecosystem is semi-enclosed with limited and poor tidal flushing and has a total water surface area of about 880 ha (Yahya et al., 2016).

Setiu Wetlands has been divided into nine inter-connected ecosystems that served high biodiversity of flora and fauna from Penarik village to Beting Lintang village. This area is in making headway to be gazette by the state government as a protected area. This study area is of primary oceanographic importance since it is one of the largest estuaries of the east coast of Peninsular Malaysia which two main river systems flow, the Setiu River and Chalok River (Figure 1). These areas are of a diverse ecosystem with functional natural resources; an enormous array of biological diversity with the combination of terrestrial, coastal and riverine fishing activities.

For the diagnosis, all samples of $M$. rosenbergii were collected within several hours and were immediately taken into the laboratory and rapidly processed. The samples were collected for the parasitology test. 


\subsection{Parasitology Study}

According to Tuntiwaranuruk et al. (2004), tissue $\left(4 \mathrm{~mm}^{2}\right)$ from each sample was cut out at a mid-ventral position from the inner and outer parts of the gut and intestine. The tissue was immediately squashed between glass slides and observed under a light microscope by differential interference lens optics (Nikon Microscopes Eclipse 80i) and captured for micrograph. In this study, samples for prawns are specifically chosen as the target area of infections according to the previous report.

\subsection{Prevalence and Mean Intensity Study}

Two descriptions of parasite distribution are used: prevalence and infection intensity (Ihwan et al., 2013). Prevalence describes the proportion of individuals in the population that are infected by a specific parasite or pathology and is calculated as:

Prevalence $=$ Number of prawn with gregarine

Number of prawn analyzed

Infection intensity is calculated as the average number of occurrences of the gregarine or pathology in infected bivalves. This is a measure of the intensity of infection in infected individuals.

Intensity of Infection = Total number of gregarine

Number of prawn with gregarine

\subsection{Morphology Identification of Parasites Study}

Morphological identification of the parasites is referring to an expert from the journal. The chosen species are depended on the similarity of parasites characteristics

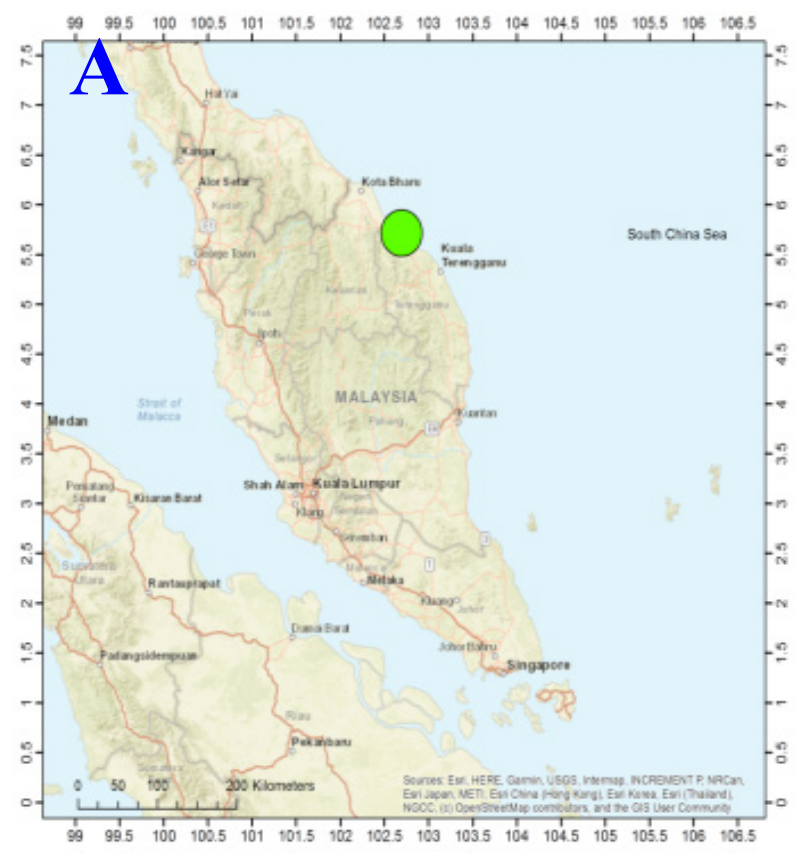

and previously infected hosts. Have been studying the case of gregarine infection in prawns and have developed the lifecycles of the parasites. The study of morphological characteristics is referring to Tuntiwaranuruk et al. (2004).

\subsection{Micrograph}

For micrographs, samples were viewed live under the light microscope (Nikon Eclipse 80i) at Advanced Microscope Laboratory, Institute of Tropical Aquaculture (AKUATROP), Universiti Malaysia Terengganu (UMT). Ten samples were selected for micrograph viewing. The measurement of length and width of the gregarine were recorded.

\subsection{Drawing}

The live samples were placed into the glass slide in the condition of a semi-dry slide. The selected samples were then viewed under light microscopes and directly drawn using a Leica Lucida camera tube. The captured sample was sketched on A4 paper and later transferred to tracing paper for detailed morphology drawing. Lucida camera tubes attached with Leica compound microscopes were used for drawing the parasites. The important characteristics were focused to confirm the internal and external parts of parasites which is stated for identification purposes.

\subsection{Data Analysis}

SPSS version 24 software were used as a tool for analysis. The selection of the test method formula is depended on the objectives of the study. The prevalence and odds ratio study were calculated using Microsoft Excel version 2010.

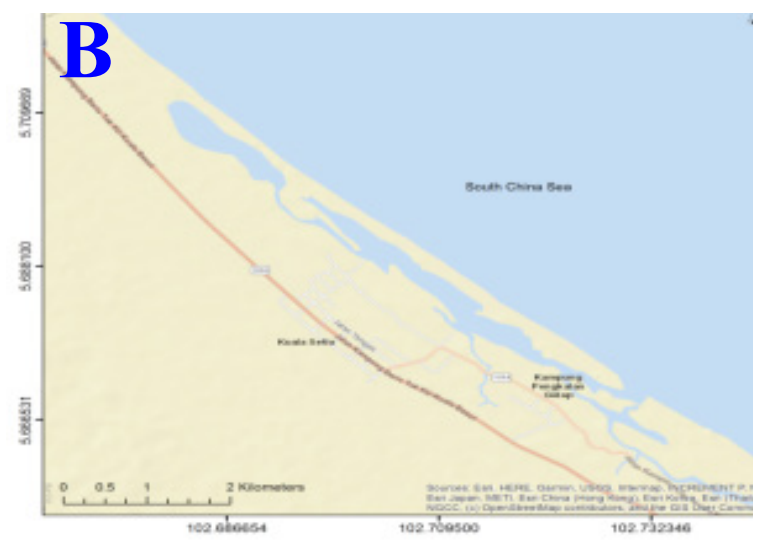

Figure 1. Maps of Setiu Lagoon which samples were collected during this study. (A) Location of Setiu Lagoon which situated as the East Coast of Peninsular Malaysia and (B) location of Setiu lagoon in the state of Terengganu 


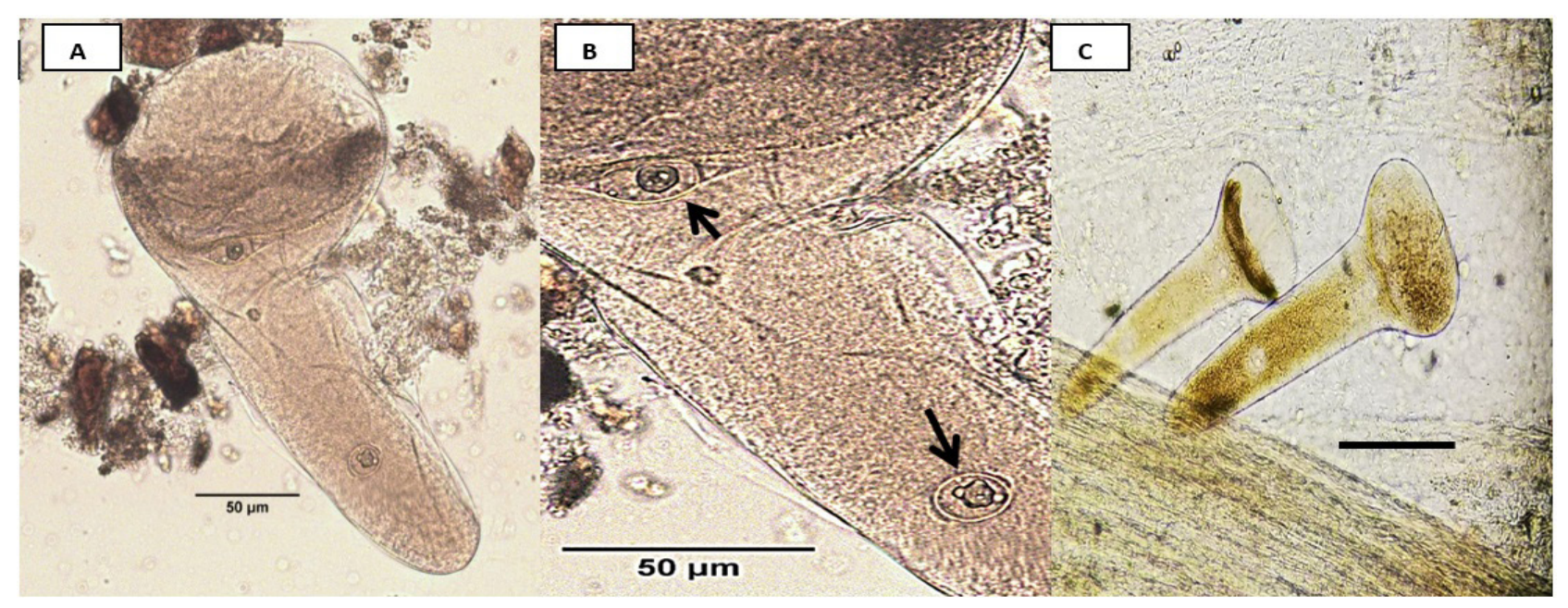

Figure 2. Two nucleuses were captured (B) in the samples. Structure of gamont (A and C) that were collected from the freshwater prawn, M acrobrachium rosenbergii from Setiu Lagoon $(B a r=50 \mu \mathrm{m})$.
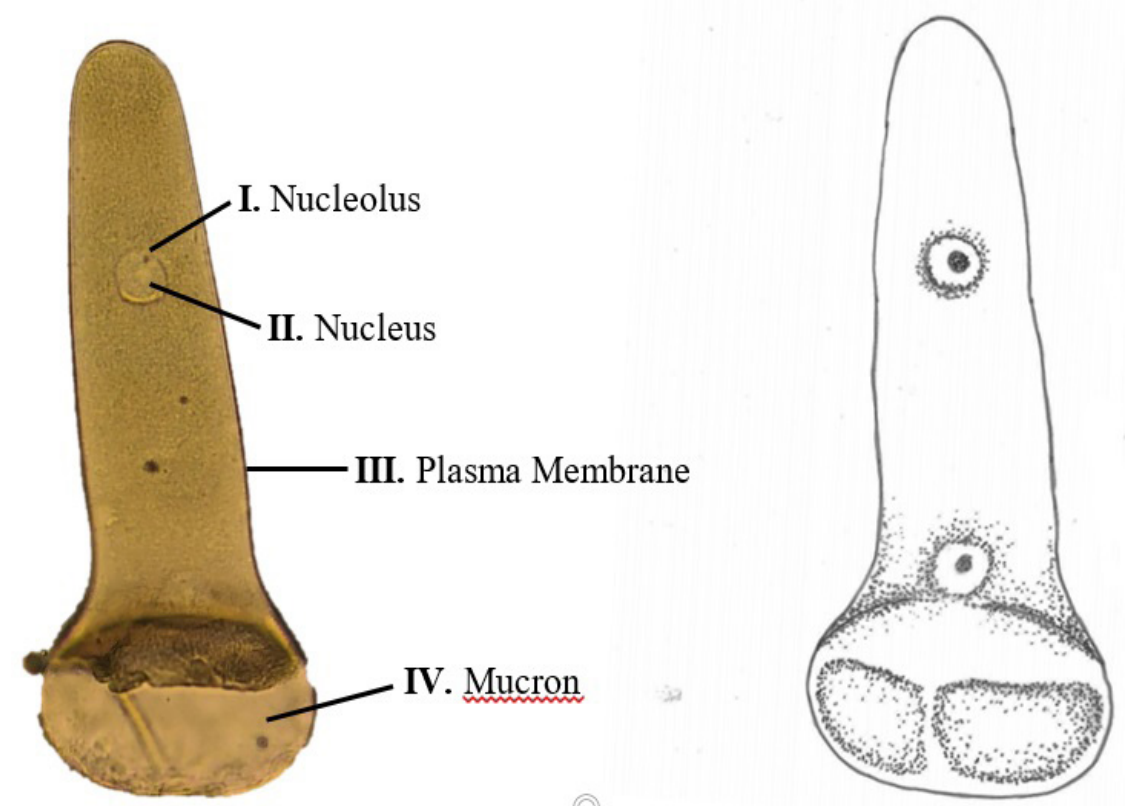

Figure 3. Structure of gamont that found in the digestive tract of freshwater prawn from Setiu lagoon. (Bar $=10 \mu \mathrm{m})$
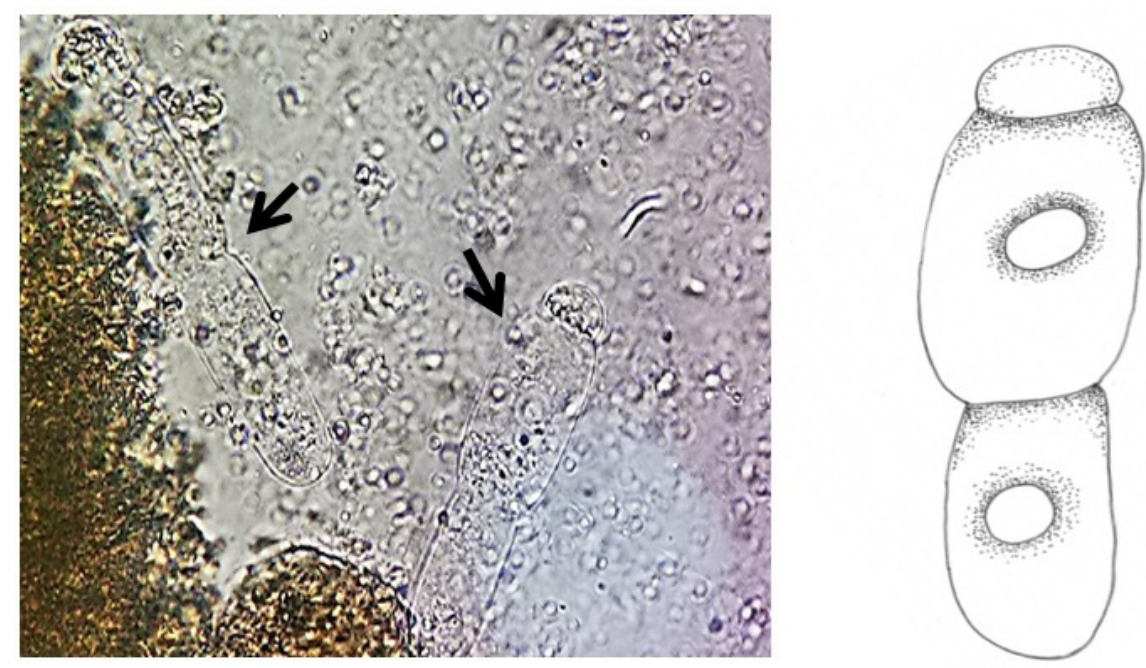

Figure 4. Structure of syzygy with two nucleolus (arrow) fills with nucleus at one-third of parasites body at both ends. $(\mathrm{Bar}=10 \mu \mathrm{m})$ 
JIPK. Volume 14 No 1. April 2022 / Optimization of Medium Composition for Streptomyces sp. PB2 Chitinase...

Table 1. One-Sample statistics analysis for gregarine parasites found on M. rosenbergii from Setiu lagoon

\begin{tabular}{lllll}
\hline & N & Mean & Std. Deviation & Std. Error Mean \\
\hline Weight & 33 & 23.882 & 32.230 & 5.611 \\
Length & 33 & 124.839 & 33.294 & 5.796 \\
Sex & 33 & 0.3 & 0.467 & 0.081 \\
Infection & 33 & 0.42 & 0.502 & 0.087 \\
\hline
\end{tabular}

Table 2. One-sample test with the value of confidence interval of the difference for gregarine parasites found on M. rosenbergii from Setiu lagoon.

Test Value $=0$

\begin{tabular}{lrrrrrr}
\hline & & & & & & \multicolumn{2}{c}{$\mathbf{9 5 \%}$ Confidence Interval of the Difference } \\
\cline { 6 - 7 } & & tf & Sig. (2-tailed) & Mean Difference & Lower & Upper \\
\hline Weight & 4.257 & 32 & 0 & 23.882 & 12.454 & 35.311 \\
Length & 21.54 & 32 & 0 & 124.839 & 113.033 & 136.644 \\
Sex & 3.73 & 32 & 0,001 & 0.303 & 0,14 & 0.47 \\
Infection & 4.856 & 32 & 0 & 0.424 & 0.25 & 0.6 \\
\hline
\end{tabular}

Table 3. Gregarine parasites found infected in crustaceans reported worldwide

\begin{tabular}{|c|c|c|c|c|}
\hline Location & Gregarine species & Host & $\begin{array}{c}\text { Measurement } \\
(\mu \mathrm{m})\end{array}$ & References \\
\hline India & N. rosenbergii & M. rosenbergii & $608.0-1116.5$ & Shanavas et al. (1989) \\
\hline India & N. sundarbanensis & P. monodon & $11.5-50.5$ & $\begin{array}{l}\text { Chakraborti and Bandyopadhyay } \\
\text { (2010) }\end{array}$ \\
\hline India & $N$. annulipes & Uca sp. & $213.0-317.0$ & Prasadan and Janardanan (2001) \\
\hline India & N. quadratum & Uca sp. & $404.0-678.0$ & Prasadan and Janardanan (2001) \\
\hline India & N. messor & Uca sp. & $114.0-178.0$ & Prasadan and Janardanan (2001) \\
\hline India & $N$. indicus & P. indicus & $494.0-1047.0$ & Prema and Janardanan (1990) \\
\hline Ecuador & N. marinus & L. vannamei & $600.0-700.0$ & Jimenez et al. (2002) \\
\hline Thailand & Nematopsis sp. & P. monodon & $230.0-361.0$ & Tuntiwaranuruk et al. (2008) \\
\hline Malaysia & Nematopsis spp. & M. rosenbergii & $219.9-523.8$ & Choong (2011) \\
\hline Malaysia & \multicolumn{2}{|c|}{ Unidentified gregarine $M$. rosenbergii } & $229.4-271.7$ & Present Study \\
\hline
\end{tabular}




\section{Results and Discussion}

Gregarine gamont and syzygy were discovered in the gut and intestine of M. rosenbergii from Nyatoh River, Setiu Lagoon. Observation using light microscopy (Nikon Eclipse 80i) showed that gamont was presumably gliding freely in the lumen or penetrate in the epithelium wall cells. Two spherical nuclei were seen on the structure of the body of the parasites. Location of nuclei generally situated at one-third of the body from both ends. Every sample that was found is characterized with epimerite structure which is functional as an anchoring part in their host gut and intestine. Two structures belonging to different stages of parasites were found in this study, which are gamont and syzygy structure stages.

The total number of 33 samples $(\mathrm{N}=33)$ with mean weight $(23.88 \pm 32.23)$ and length $(124.84 \pm 33.29)$ of freshwater prawn was diagnosed for gregarine parasites (Table 1). The prevalence of the parasites is $42.4 \%$ with $95 \%$ CI $25.6 \%$ to $59.3 \%$ and value of Odd Ratio (OR) 0.74 (CI 0.29 to 1.88 ). One sample T-test was applied for data analysis and the result showed $p$-value $(\mathrm{p}<0.05)$ to be significant especially for weight, length, sex, and infections (Table 2). For the parasite measurement, the mean length is $244.74 \pm 16.53$ and the mean length is $54.04 \pm 8.42$, respectively. From this study, the size of gregarine parasites are closely related to the parasites that have been found by Prasadan and Janardan (2001) and Tuntiwaranuruk et al. (2008) with the measurement range size is $213.0-317.0 \mu \mathrm{m}$ and $230.0-361.0 \mu \mathrm{m}$, respectively. Detailed information on the measurement range size of the present study and previous report are varied (Table 3).

Studies of the parasite of prawn are likely to be important due to the commercial value of the prawn. Parasites may be considered as a pathogenic agents who affected the growth and reproductive performance of their host. The previous study had carried out a parasitological diagnosis of freshwater prawn, $M$. rosenbergii, in different geographical regions which relate to the defense mechanism and their economic importance to the aquaculture industry. Investigation study about gregarine parasites of $M$. rosenbergii in Malaysia is still lacking. Even though the study of this parasite has been described in other parts of the world region, it might not be identical and their pathogenicity could be different to those found in Malaysia.

Disease outbreaks in this prawn as a host will occur if the knowledge of this parasite was not critically explored. Thus, the investigation of the occurrence of gregarine parasites in the prawn was carried out with detailed morphological characteristic study for identification purposes. The morphological characteristic of the gregarine found in this study is closely related to reports, presumably because it originates from the same region. Research done by Shanavas et al. (1989) showed different characteristics and sizes of Nematopsis rosenbergii even though it was found in the same host as in the present study (Table 3).

Fajer-Avila et al. (2005) explained that the presence of gregarine is usually associated with the slow growth of the prawn. Nonetheless, the presence of this gregarine parasite can be seen in the wild and it can indicate the situation that related to present if no action was carried out on the prawn for broodstock purposes. The potential of heavy infection by this gregarine will increase the absorption of nutrients and yet can decrease the nutrients that are prioritized for the development of prawns. The infection also can result in a lesion due to the penetration of the epimerite structure which can damage the epithelium cell and can lead to secondary infection of bacteria and virus which eventually caused mortalities.

\section{Conclusion}

Investigation study about gregarine parasites of $M$. rosenbergii in Malaysia is still lacking. The prevalence of the parasites in this study is $42.4 \%$ with $95 \%$ Cumulative Index (CI) $25.6 \%$ to $59.3 \%$ and value of Odd Ratio $(\mathrm{OR})$ is $0.74(\mathrm{CI}=0.29$ to 1.88$)$. Two structures belonging to different stages of parasites were found in this study, which are gamont and syzygy structure stages. The morphological characteristic of the gregarine found in this study is closely related to the previous report. Further study using genetics applications is needed to confirm the species.

\section{Acknowledgement}

This study was partially supported by the Higher Institution Centre of Excellence (HICoE), Institute of Tropical Aquaculture and Fisheries, Universiti Malaysia Terengganu and UMT Translational Research Grant.

Thank you to the Faculty of Veterinary Medicine, Universiti Putra Malaysia (UPM) and Institute of Tropical Aquaculture and Fisheries (AKUATROP) staff for all their help and kind supports throughout the study.

\section{Authors' Contributions}

All authors have contributed to the final manuscript. The contribution of each author is as follow, 
JIPK. Volume 14 No 1. April 2022 / Optimization of Medium Composition for Streptomyces sp. PB2 Chitinase...

Mohd Ihwan Zakariah; designed study. Hassan Mohd Daud and Mhd. Ikhwanuddin Abdullah; co-supervisor and reviewed manuscript. Wahidah Wahab; measure the parasites. Farizan Abdullah; collect the sample. Nor Asma Husna Mohammed Yusoff; analysed the data. Ahmad Shuhaimi Draman; process the sample. Marina Hassan; revised the main conceptual ideas and critical revision of the article. All authors discussed the results and contributed to the final manuscript.

\section{Conflict of Interest} ing interests.

The authors declare that they have no compet-

\section{Funding Information}

UMT Translational Research Grant (Vot 53303) and Higher Institution Centre of Excellence (HICoE), Institute of Tropical Aquaculture and Fisheries (AKUATROP), Universiti Malaysia Terengganu (Vot 66955).

\section{References}

Chakraborti, J., \& Bandyopadhyay, P. K. (2010). First record of a parasitic septate gregarines (Apicomplexa: Sporozoea) in the shrimp Peneaus monodon in Sundarbans of West Bengal. Journal of Parasitic Disease, 34(1):40-43.

Choong, F. C. (2011). The study of parasites infestation on wild giant freshwater prawn, Macrobrachium rosenbergii in Peninsular Malaysia. Thesis. Terengganu: AKUATROP.

Erazo-Pagador, G. (2010). A parasitological survey of slipper-cupped oyster (Crassostrea iredalei Faustino, 1932) in the Philippines. Journal of Shellfish Research, 29:177-179.

Fajer-Avila, E., Covarrubias, M. S. M., Abad-Rosales, S., Roque, A., Meza-Bojorquez, P., Meza-Bojorquez, P., \& Hernandez-Gonzalez, C. (2005). Effectiveness of oral ElancobanTM and Avimix-STTM against Nematopsis (Apicomplexa: Porosporidae) gametocysts infecting the shrimp Litopenaeus vannamei. Aquaculture, 244:11-18.

Hofman, E., Bushek, D., Ford, S., Guo, X., Haidvogel, D., Hedgecock, D., Klinck, J., Milbury, C., Narvaez, D., Powell, E., Wang, Y., Wang, Z., Wilkin, J., \& Zhang, L. (2009). Understanding how disease and environment combine to structure resistance in estuarine bivalve populations. Oceanography, 22(4):212-231.
Ihwan, M. Z., Shaharom-Harrisson, F., Marina, H., \& Wahidah, W. (2013). A Comparative prevalence study of ectoparasites in wild and cultured grouper before and after transportation. Journal of sustainability of science and management, 8(1):121-125.

Jimenez, R., de Barniol, L., \& Machuca, M. (2002). Nematopsis marinus $\mathrm{n}$. $\mathrm{sp}$., a new septate gregarine from cultured penaeid shrimp Litopenaeus vannamei (Boone), in Ecuador. Aquaculture, 33:231240.

Kua, B. C., \& Taha, M. S. (2004). A preliminary observation of parasitic infestation on blood cockles (Anadara granosa) and tropical oyster (Crassostrea iredalei) in Northern Peninsular Malaysia. Malaysian Fisheries Journal, 3:125-129.

Kua, B. C., Salleh, M., \& Noraziah, M. (2013). A case study of protozoan parasite gregarine Nematopsis spp. (Apicomplexa: Sporozoa) infestation in mangrove oyster Crassostrea belcheri imported from Thailand. Pertanika Journal of Tropical Agricultural Science, 36(3):217-224.

Lightner, D. V. (1996). A handbook of Shrimp pathology and diagnostic procedures for disease of cultured Penaeid Shrimp. Baton, Rouge: World Aquaculture Society.

OIE. (2016). OIE International Standards: The key to better aquatic animal health and welfare ( $7^{\text {th }}$ ed.). World Organization for Animal Health.

Prasadan, P. K., \& Janardanan, P. K. (2001). Three new species of Gregarines (Apicomplexa: Sporozoea: Porosporidae) in the Estuarine Crabs from Kerala, India. Acta Protozool, 40:303-309.

Prema, S., \& Janardanan, K. P. (1990). Two new species of cephaline gregarines (Apicomplexa: Sporozoa) from the marine prawn Penaeus indicus H. Milne Edwards. Acta protozoologica, 29(4):365-373.

Prytherch, H. F. (1940). The life cycle and morphology of Nematopsis ostrearum, sp. nov., a gregarine parasite of the mud crab and oyster. Journal of Morphology, 66:39-65.

Shanavas, K. R., Prasadan, P. K., \& Janardanan, K. P. (1989). Nematopsis rosenbergii n. sp. (Apicomplexa: Cephalina) from the brackish water prawn, Macrobrachium rosenbergii (de Man). Archiv für Protistenkunde, 137(2):161-164.

Sindermann, C. J. (1990). Principal Diseases of Marine Fish and Shellfish. $\left(2^{\text {nd }} e d.\right)$. Diseases of marine 
shellfish. San Diego: Academic Press, Inc.

Tuntiwaranuruk, C., Chalerm, K., Upatham, E. S., Kruatrachue, M., \& Azevedo, C. (2004). Investigation of Nematopsis spp. oocysts in 7 species of bivalves from Chonburi province, Gulf of Thailand. Diseases of Aquatic Organisms, 58:47-53.

Tuntiwaranuruk, C., Chalermwat, K., Pongsakchat, V., Meepool, A., Upatham, E. S., \& Kruatrachue, M. (2008). Infection of Nematopsis oocysts in different size classes of the farmed mussel Perna viridis in Thailand. Aquaculture, 281(1-4):12-16.
Yahya, N., Zakaria, N. Z., Taufeq, Z. M., Rosli, N. S., \& Bachok, Z. (2016). Ecology of bivalves in the Lagoon Area of Setiu Wetlands, Terengganu, Malaysia. Middle East Journal of Scientific Research, 24(6):2145-2151.

Yee, J. N. J., \& Hassan, M. (2020). Prevalence of parasite infestations among four commercially exploited wild shellfish species in Setiu Wetland, Terengganu, Malaysia. Universiti Malaysia Terengganu Journal of Undergraduate Research, 2(2):57-66. 